\title{
Internship Competencies in General Medicine (Monastir-Tunisia)
}

\section{Belguith AS ${ }^{1}$, Koubaa AA $^{2^{*}}$, Boughalleb W' ${ }^{2}$, Abroug H $^{1}$, Fredj MB ${ }^{1}$, Zemni I $^{1}$, Bouslah AM ${ }^{1}$ and Soltani MS ${ }^{1}$}

${ }^{1}$ Department of Epidemiology and Preventive Medicine, University Hospital of Monastir, Tunisia

${ }^{2}$ Family medicine, University Hospital of Monastir, Tunisia

"Corresponding author: Koubaa AA, Family physician, University Hospital of Monastir, Tunisia, Tel: 21698651904; E-mail: abdelkafiafifa@yahoo.fr

Received date: July 05, 2018; Accepted date: July 17, 2018; Published date: July 23, 2018

Copyright: $\odot 2018$ Belguith AS, et al. This is an open-access article distributed under the terms of the Creative Commons Attribution License, which permits unrestricted use, distribution, and reproduction in any medium, provided the original author and source are credited.

\begin{abstract}
Background: The internal trainees learning is an essential deal for acquiring competencies in general practice. The internship book serves for their pre-post evaluation.
\end{abstract}

Objective: We aimed at describing the intern's improvement of skills during training.

Methods: We conducted a quasi-experimental study, including interns having carried out their stage in general medicine, from March 2008 to February 2015. Our main outcome was comparing pre-post stage acquisitions.

Results: Within the period study, 566 interns realized the internship. Acquisitions improvement rate increased significantly after stage in all items for the Lickert scale very good and excellent. Self-evaluation rates pre-post stage passed from $1.7 \%-34.5 \%$ for primary care current activities and from $2.3 \%-35.1 \%$ for care globality. For technical abilities, the rate passed from $7.5 \%-22.8 \%$ for gastroenterology skills. The highest non-response rate was notified for care coordination passing from $2.6 \%-10.4 \%$ and for ophthalmology (from 18.8\%-27.8\%). However, the best student competence was care coordination (26.1\%). The highest increasing technical skill item was unregistered in otoscopic examination (24.9\%), the lowest was practice and reading an intradermal reaction (5.3\%).

Conclusion: The apprehension of some competencies must be developed by including family doctor trainer in Tunisians faculties of medicine.

Keywords: General practice; Education; Medical; Training support; Clinical competence; Teaching

\section{Introduction}

The general medicine (GM) internship is essential to acquire competencies and skills; Preparing internal trainees to the professional practice [1-4]. In Tunisia, medical training is mainly performed in university hospital; GM occupied a residual place [5]. In the faculty of medicine of Monastir, the community medicine department coordinate training of internal trainees in general practice and their assessment [6]. This internship was realized in a private practice, in a health care center or an in general hospital. The internal trainees were guided by the supervising trainer in each department and, must be evaluated at the completion of the training on the core competencies, and co-signed by the internal trainees [7]. Several pedagogical tools have been used to assess internal trainees acquisitions and competencies, such internship book $[2,8]$. It is a guide, defining the objectives and abilities to be acquired by the internal trainees; In addition, it serves for self-assessment before internship and at its end [4]. We aimed at describing the rate of the intern's acquisitions, competency and technical ability, related to the GM and to identify items with higher and lower change.

\section{Methods}

\section{Study design}

It is a quasi-experimental study (pre-post evaluation study) during the period of seven years from March 2008 to February 2015.

\section{Study setting}

Established in October 1980, and located in the center of Tunisia, the Monastir faculty of medicine is one of four faculty of medicine in Tunisia. The average number of registered students passed from 45 in 1980 to 1762 in 2015 . The number of faculty graduates touched 2984 in 2016. Education system destined to external student stays five years followed by 2 years of internal training.

During period study, Monastir governorate included 97 public health centers, two regional hospitals and one university hospital. GM was developed in community department, which join faculty to health public care center and regional hospitals. Since 1992, GM trainers had experience in family medicine and collaborated with Canadian and English family medicine. They have benefited from training with Canadian family medicine, therefore qualified in the field. Also, general doctor's trainer participated in internship-book conception.

\section{Population}

We have included all the intern trainees having carried out their stage in community department. Within the period study, 566 students 
realized a GM internship. All students received the same training input.

\section{Sample size}

A pilot survey was conducted at the beginning of the study to determine the sample size, which revealed that the overall knowledge of the principles of general medicine at the beginning of the internship was $15.3 \%$ and that it rose to $26.4 \%$ at the end. For the determination of the size of the sample for matched sample to attain $80 \%$ power, at $\alpha=0.05$, we used Mgee formula.

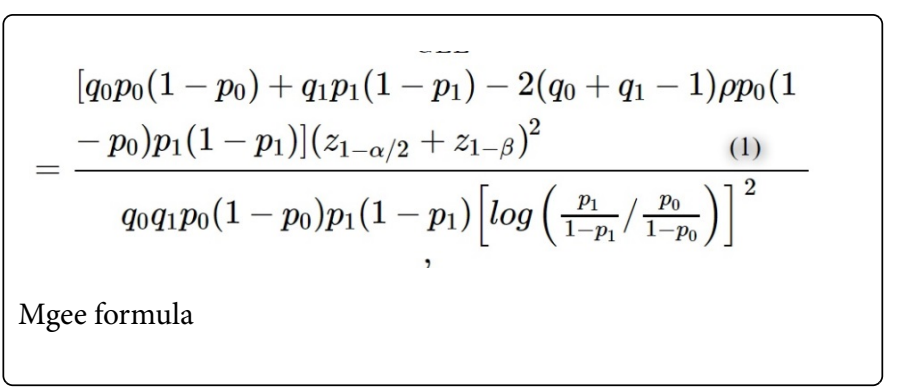

The sample size must be at least 258 . In our study, we have included all internship from 2008 to 2015 .

\section{Methodology}

In Monastir faculty of medicine, the training of the internal trainees takes place in six quadrimester of which five take place at the level of the hospital-university structures. The sixth quadrimester coordinated by the community department. During this course, each trainee benefited from the 4th month placement at two training sites from general hospitals or an ambulatory center. At the end of stage, internal trainees were evaluated by Objective Structured Clinical Examination (OSCE) [9].

We have used the internship book to evaluate internal trainees apprentice ship in GM. The state of knowledge and technical skills were appreciated, under the control of internal trainee's clinical trainee, at the beginning and the end of the course. Collect of internship book was carried out anonymously in community department. Variables included, first, competency objects composed by 5 dimensions, with primary care current activities (16 items), care globality ( 7 items), care coordination (15 items), care continuity (15 items) and public health care (12 items) [10].

Second, internship book contains technical abilities with medical and surgical dimensions (83 items). These items were evaluated according to a Likert scale ranging from 1 to 5 (1-Bad, 2-Medium, 3Well, 4-Very good, 5-Excellent). We have calculated the level of change by subtracting the pre-post Likert scale. Then, we have considered three groups: Stabilization, (Likert change=zero), moderate change (Likert change $=$ one) or good change (Likert change $\geq 2$ ). The reliability of internship-book (consistency of the scores obtained by the same individuals examined at different times) was calculated. We used Cronbach's alpha to determine internal consistency of the total scale for competency objects and technical ability before and after internship (Table 1)

\begin{tabular}{|l|l|l|l|l|}
\hline & \multicolumn{2}{|l|}{$\begin{array}{l}\text { Competency objects } \\
\text { items) }\end{array}$} & $\begin{array}{l}\text { Technical } \\
\text { items) }\end{array}$ & ability (9 \\
\cline { 2 - 5 } \multirow{2}{*}{$\begin{array}{l}\text { Scale Cronbach's } \\
\text { alpha }\end{array}$} & Before & After & Before & After \\
\cline { 2 - 5 } & 0.893 & 0.823 & 0.886 & 0.933 \\
\hline $\begin{array}{l}\text { Spearman-Brown } \\
\text { Coefficient }\end{array}$ & 0.855 & 0.814 & 0.766 & 0.744 \\
\hline
\end{tabular}

Table 1: Reliability of internship-book.

\section{Statistical analysis}

The collection and analysis of statistical data were performed on hardware SPSS Version 20. We used the test Mc-Nemar at the 5\% significance level to evaluate changes of variables percentages before and after.

\section{Results}

Competencies had significantly improved at the end of GM internship in all items. In fact, self-assessment rates passed from $1.7 \%-34.5 \%$ for primary care current activities and from 2.3\%-35.1\% for care globality. For technical abilities, the rates passed from $7.5 \%-22.8 \%$ for gastro-enterology skills, from $12.0 \%-24.1 \%$ for pneumology skills, from $9.3 \%-21 \%$ for urology skills and from 3.3\%-13.2\% for dermatology skills. The highest non-response rate was notified for care coordination passing from 2.6\%-10.4\%, for ophthalmology in technical ability, it was $18.8 \%$ before stage and $27.8 \%$ after GM stage (Table 2). From beginning to end of stage, the highest student competence, increasing for 2 points and more was care coordination $(26.1 \%)$. For technical abilities, the greatest performance was notified in gastro-enterology (18.9\%) (Table 3).

\begin{tabular}{|l|l|l|l|l|l|l|l|l|l|l|}
\hline & \multicolumn{9}{|c|}{ Before stage } & \multicolumn{4}{c|}{ After stage } & $P^{*}$ \\
\cline { 2 - 10 } & Ability (number of items) & $\begin{array}{l}\text { No } \\
\text { response }\end{array}$ & $\begin{array}{l}\text { Low- } \\
\text { moderate }\end{array}$ & Good & $\begin{array}{l}\text { Very good- } \\
\text { excellent }\end{array}$ & $\begin{array}{l}\text { No } \\
\text { response }\end{array}$ & $\begin{array}{l}\text { Low- } \\
\text { moderate }\end{array}$ & Good & $\begin{array}{l}\text { Very } \\
\text { excellent }\end{array}$ \\
\hline \multicolumn{7}{|c|}{ Good- } \\
\hline $\begin{array}{l}\text { Primary care currentencies dimensions } \\
\text { activities (16) }\end{array}$ & $10(1.6)$ & $352(54.7)$ & $271(42.1)$ & $11(1.7)$ & $56(8.7)$ & $57(8.9)$ & $309(48.0)$ & $222(34.5)$ \\
\hline Care Globality (7) & $20(3.1)$ & $370(57.5)$ & $239(37.1)$ & $15(2.3)$ & $64(9.9)$ & $66(10.2)$ & $228(44.7)$ & $226(35.1)$ & 0.000 \\
\hline Care Coordination (15) & $17(2.6)$ & $442(68.6)$ & $173(26.9)$ & $12(1.9)$ & $67(10.4)$ & $120(18.6)$ & $295(45.8)$ & $162(25.2)$ & 0.000 \\
\hline
\end{tabular}


Citation: Belguith AS, Koubaa AA, Boughalleb W, Abroug H, Fredj MB, Zemni I, Bouslah AM, Soltani MS (2018) Internship Competencies in General Medicine (Monastir-Tunisia). J Gen Pract (Los Angel) 6: 362. doi:10.4172/2329-9146.1000362

Page 3 of 5

\begin{tabular}{|c|c|c|c|c|c|c|c|c|c|}
\hline Care Continuity (15) & $25(3.9)$ & $475(73.8)$ & $124(19.3)$ & $20(3.1)$ & $60(9.3)$ & $111(17.2)$ & $349(54.2)$ & $124(19.3)$ & 0.000 \\
\hline Public health (12) & $30(4.7)$ & $502(78.0)$ & $95(14.8)$ & $17(2.6)$ & $58(9.0)$ & $238(37.0)$ & $246(38.2)$ & $102(15.8)$ & 0.000 \\
\hline \multicolumn{10}{|c|}{ Technical abilities } \\
\hline Dermatology (11) & $46(7.1)$ & $516(80.1)$ & $61(9.5)$ & $21(3.3)$ & $105(16.5)$ & $328(50.9)$ & $126(19.6)$ & $85(13.2)$ & 0.000 \\
\hline Ophtalmology (8) & $121(18.8)$ & $398(61.8)$ & $105(16.3)$ & $20(3.1)$ & $179(27.8)$ & $270(41.9)$ & $119(18.5)$ & $76(11.8)$ & 0.000 \\
\hline Oto-rhino- laryngology (9) & $68(10.6)$ & $431(66.9)$ & $108(16.8)$ & $37(5.7)$ & $124(19.3)$ & $257(39.9)$ & $169(26.2)$ & $94(14.6)$ & 0.000 \\
\hline Gastrology (8) & $83(12.9)$ & $435(67.5)$ & $78(12.1)$ & $48(7.5)$ & $132(20.5)$ & $272(42.2)$ & $93(14.4)$ & $147(22.8)$ & 0.000 \\
\hline Pneumology (7) & $101(15.7)$ & $276(42.9)$ & $190(29.5)$ & $77(12.0)$ & $143(22.2)$ & $160(24.8)$ & $186(28.9)$ & $155(24.1)$ & 0.000 \\
\hline Chirurgy (9) & $63(9.8)$ & $427(66.3)$ & $110(17.1)$ & $44(6.8)$ & 109 (16.9) & $302(46.9)$ & $157(24.4)$ & $76(11.8)$ & 0.000 \\
\hline Gynecology (10) & $84(13)$ & $403(62.6)$ & $112(17.4)$ & $45(7)$ & $135(21)$ & $247(38.4)$ & $157(24.4)$ & $105(16.3)$ & 0.000 \\
\hline Urology (4) & $102(15.8)$ & $366(56.8)$ & $116(18)$ & $60(9.3)$ & $163(25.3)$ & $234(36.3)$ & $112(17.4)$ & $135(21.0)$ & 0.000 \\
\hline Reanimation (11) & $111(17.2)$ & $335(52.0)$ & $157(24.4)$ & $41(6.4)$ & $152(23.6)$ & $211(32.8)$ & $181(28.1)$ & $100(15.5)$ & 0.000 \\
\hline Other (8) & $93(14.4)$ & $285(44.3)$ & $183(28.4)$ & $83(12.9)$ & $143(22.2)$ & $140(21.7)$ & $206(32.0)$ & $155(24.1)$ & 0.000 \\
\hline
\end{tabular}

Table 2: Self-evaluation rates distribution of competencies and technical abilities by the internship in family medicine (Likert scale).

\begin{tabular}{|c|c|c|c|}
\hline Items & $\begin{array}{l}\text { Stabilization } \\
\text { N\% }\end{array}$ & $\begin{array}{l}\text { Likert change=1 } \\
\mathrm{N} \%\end{array}$ & $\begin{array}{l}\text { Likert change } \geq \\
2 \\
\mathrm{~N} \%\end{array}$ \\
\hline \multicolumn{4}{|c|}{ Competencies dimensions } \\
\hline $\begin{array}{l}\text { Primary care current } \\
\text { activities }\end{array}$ & $137(23.4)$ & $359(61.4)$ & $89(15.3)$ \\
\hline Care Globality & $126(22.0)$ & $327(57.0)$ & $121(21.0)$ \\
\hline Care Coordination & $154(26.8)$ & $271(47.1)$ & $150(26.1)$ \\
\hline Care Continuity & $140(23.4)$ & $333(58.0)$ & $101(17.6)$ \\
\hline Public health & $200(34.3)$ & $284(48.6)$ & $100(17.1)$ \\
\hline \multicolumn{4}{|c|}{ Technic abilities } \\
\hline Dermatology & $313(58,9)$ & $142(26,7)$ & $76(14,3)$ \\
\hline Chirurgical technic & $320(61.3)$ & $168(32.2)$ & $34(6.5)$ \\
\hline Ophtalmology & $272(59.6)$ & $135(29.5)$ & $50(11 \%)$ \\
\hline ORL & $287(56.1)$ & $167(32.6)$ & $58(11.3)$ \\
\hline Gastro-Entérology & $321(63.2)$ & 91 (17.9) & $96(18.9)$ \\
\hline Urology & $270(56.6)$ & $143(30)$ & $64(13.4)$ \\
\hline $\begin{array}{l}\text { Gyneco-Obstetrical } \\
\text { technic }\end{array}$ & $258(51.1)$ & $205(40.6)$ & $42(8.3)$ \\
\hline Pneumology & $278(55.9)$ & $169(34)$ & $50(10)$ \\
\hline Rea-Anesthesia & $288(59.5)$ & $157(32.4)$ & $39(8.1)$ \\
\hline Others & $259(52.1)$ & $175(35.2)$ & $63(12.7)$ \\
\hline
\end{tabular}

The highest increasing competence item was making a transversal and longitudinal data collection (35.1\%). The lowest item was participating in the evaluation of practices (10.9\%) (Figure 1). The highest increasing technical skill item was unregistered in otoscopic examination $(24.9 \%)$, the lowest was practice and reading an intradermal reaction (5.3\%) (Figure 2).

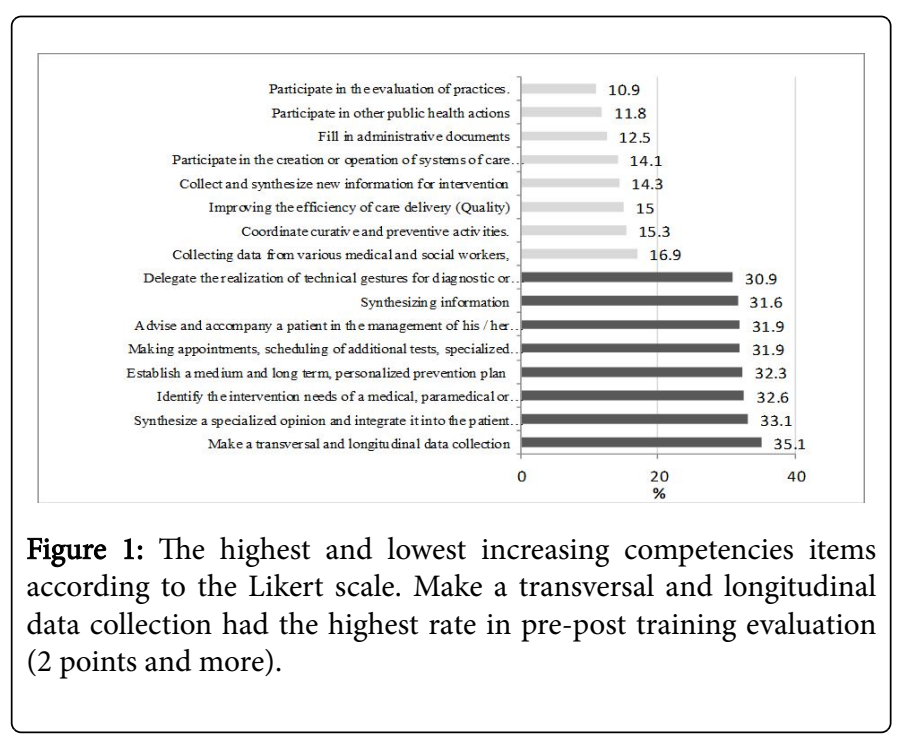

Table 3: Self-evaluation change rates by internship in family medicine (Likert scale). 


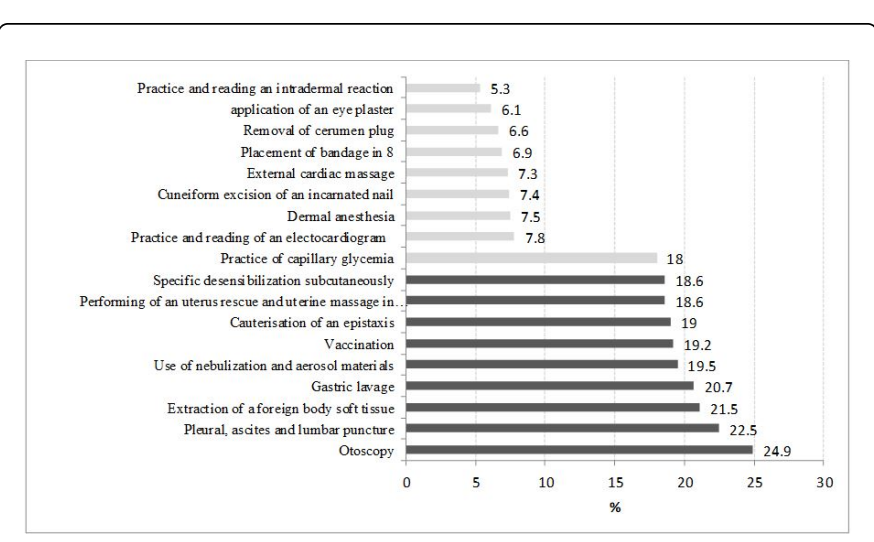

Figure 2: The highest and lowest increasing technical skills items according to the Likert scale. Otoscopic examination had the highest rate in pre-post training evaluation (2 points and more).

\section{Discussion}

During an eight years study, we have confirmed that training was beneficial for acquiring competencies and technical abilities if realized by family physician. In Nord African literature, few published studies have focused on the acquisition of skills and abilities in general practice. We used, the internship book as a mean of evaluation as some literature [11]. Our study demonstrated that acquisitions improvement rate increased significantly after GM stage. Our results was similar to those concluded by Barrier et al. in Nantes [11], Dory et al. in Canada [12], Johnson et al. in New York [13], Steichen et al. in Paris [4] and Baranger et al. in Angers [14], in their studies.

The highest variation had been observed for primary care current activities, and care coordination that constitutes the most common activities in general practice. The highest item was making a transversal and longitudinal data collection. These results made it reasonable to consider that the internal trainees have met the set objective of validation. The internship was beneficial as it allows the student to perfect the activities that contribute to primary health care, globality approach continuity and realization of public health objectives.

The GM internship is an opportunity to acquire some technical skills useful in their subsequent practices. Fortunately, our results converged towards a progress for familiar domains in general practice as gastro-enterology, pneumology, urology, and dermatology. For urological and gynecological abilities, our results were near respectively to those of Bigot et al [15] and Baranger et al [14]. The greatest performance was notified in gastroenterology and the most improvement was unregistered in otoscopic examination. In general, we described that internal trainees seek to learn the most common and useful gestures in general practice. We cannot neglect the possible interest of internal trainees in the acquisition of mandatory criteria for the internship validation. These results requires daily exchanges at the bedside of the patient between senior and junior mitigate the effects of self-assessment and to have a fine appreciation of acquired skills. This exchange is part of a process of pedagogical feedback and, the prerogative of the learning paradigm $[2,3,10,16]$. In our study, the highest item was making a transversal and longitudinal data collection, demonstrating internal trainee's research interest. In fact, Webster highlights, in his review, an overall need for increased sophisticated in methodological approaches to educate research in GM [1].
In our study, some students self-evaluate "low" at the end of the course, which can be explained by the lack of opportunity to attend certain gestures in the field internship, and the quality of filling of the internship book. Moreover, the time allocated by the latter for framing and coaching when filling in the internship book was not enough. It could also be a lack or absence of practice of these technical gestures relating to these disciplines by the trainees. It would be interesting to sensitize internship masters this issue and assess their problematic to form additional groups on the different areas covered by general practice, to devote more time to training $[4,16]$. The education system need if possible to allocate time for the GM dedicated solely to supervision. Further studies assessing the effects of teaching-skills training in GM are needed to stimulate development of adapted programs for the discipline. Future research should also assess how residents' teaching-skills training can affect their learners' clinical training and eventually patient care $[2,16]$.

Our study showed the importance of internship in general practice, to acquire and master different technical skills and abilities needful for the cursus of future family physicians, to offer high quality services. Although the non-response rate pre-post GM stage, may be caused by incomplete fill-in of the internship book and by the very specialized gestures in some services, considered unnecessary in general practice by internal trainees. The highest non-response rate was notified for care coordination in competency and for ophthalmology in technical abilities. However, from beginning to end of stage, the best student competence, increasing for 2 points and more according Likert scale, was care coordination, attesting an offer disparity by the trainers. According to Malinovsky et al, the majority of teachers know the existence of the internship book, but only half of them required its use [17]. Otherwise, the high number of items decreases the opportunity of acquiring skills and makes it difficult to complete the filling. This work could serve as a basis for reflection on improving the use of the internship book, which is common used end-of-training assessment tool in different specialties of medicine; The adoption of new, more efficient evaluation methods are required $[2,4,7,10,15,18]$.

We can explain internal trainees improvement described in our study by the progressively use of new teaching strategies approach in our faculty $[2,4,7,9,15,16,19]$. Their objective was promoting student expertise in healthcare, using direct supervision, lectures, interactive discussions of cases with supervisors, videotaped vignettes, roleplaying or simulated teaching activities and clinical reasoning. In fact, the simulation demonstrated its interest in the acquisition of internal trainee's knowledge and increases career potential, with a high degree of participant's satisfaction about the transfer of certain skills to clinical practice $[4,8,10,15,18]$. In Yates JE study [18] providing needs assessment to ascertain what evaluation tools was useful, simulation was the most recommended. Our perspective is to introduce the eportfolio to evaluate internal trainee's knowledge and learning $[6,15,17]$. Ann Gaba [6], enumerate several advantages of using eportfolios. First, paper based portfolios are not efficient environments to show the various abilities of students at the same time. Second, the increase of the number of users and the early adaptation of these technologies, especially by the younger generation, are likely to facilitate the use of e-portfolios. The author predicts e-portfolios becoming an indispensable part of education as both an education tool and evaluation method in many countries $[4,6,15,20]$.

However, direct observation and feedback can improve interns care skills by encouraging and giving advices to them $[2,4,10]$. The feedback can be effective by establishing respectful learning environment, 
objective feedback, direct observation, making it regular event, focusing on performance, and create and developing chances for staff [10].

Importantly, intern supervisor should facilitate a successful internship, which includes coordinating with teaching hospitals, clarifying guidelines of the internship, empowering clinical instructors, outlining clinical teaching methods, and managing media for teaching and learning [16].

It would be interesting in the future to carry out a similar national study covering the four faculties of Tunisian medicine and exploring some GM fields, such as geriatric, paediatric and psychological management of health problems and GM basic skills of primary care such as prevention, education, screening and community orientation.

\section{Study limitations}

The subjectivity of responses seems to be the main limit of our study. In addition, related to the anonym, we have not included the socio-demographic data of the students in data.

\section{Conclusion}

We noticed an acquisitions improvement by self-assessment of interns, trained by family doctors. The apprehension of some competencies must be developed by including family doctor trainer in Tunisian faculties of medicine.

\section{Acknowledgments}

We thank all the staff of GM of Monastir, especially Nouira Ridha, Bouchahda Mokhtar, Maalel Issam, Mohamed Riahi and Kamel Ben Salem. We also thank the clustering of basic health care of Monastir city and the regional health directorate. We also thank all the staff of Department of community medicine in Medicine faculty in Monastir, for the support and data collection. We offer this paper to our eminent Professor Soltani Mohammed, the department head, who died in mars 2016.

\section{References}

1. Webster F, Krueger P, MacDonald H, Archibald D, Telner D, et al. (2015) A scoping review of medical education research in family medicine. BMC Med Educ 15: 79.

2. Ross S, Poth CN, Donoff M, Humphries P, Steiner I, et al. (2011) Competency-based achievement system using formative feedback to teach and assess family medicine residents' skills. Can Fam Physician. 57: 323-330.

3. Jouquan J (2002) Levaluation des apprentissages des étudiants en formation médicale initiale. Pédagogie médicale 3: 38-52.
4. Steichen O, Georgin-Lavialle S, Grateau G, Ranque B (2015) Évaluation du savoir-faire en sémiologie clinique des étudiants en fin de deuxième cycle des études médicales. Rev Med interne 36: 312-318.

5. Zedini C, Limam M, El Ghardallou M, Mallouli M, Mestiri T, et al. La médecine générale perçue par les étudiants de la faculté de médecine de Sousse (Tunisie). Pan Afr Med J 19: 250.

6. Gaba A (2015) Development and evaluation of an e-portfolio for use in a dietetic internship program. Procedia-social and behavioral sciences 174: 1151-1157.

7. EL Ghardallou M, Ajmi Th, Bougmiza I, Zedini C, Mellouli M, et al. (2013) Les styles d'apprentissage des étudiants de la faculté de médecine de Sousse (Tunisie). Pédagogie Médicale 14: 203-215.

8. Talvard M, Olives J, Mas E (2014) Evaluation des étudiants en médecine lors de leur stage en gastro-entérologie pédiatrique par un test de concordance de script. Arch Ped 21: 372-376.

9. Phugh D (2013) Medical council of Canada guidelines for the development of objective structured clinical examination (OSCE) cases.

10. Heidarnia MA, Yasin M (2013) An evaluation on medical interns satisfaction in internship course in shahid beheshti university of medical sciences by servqaul model. Health education and health promotion (HEHP) 1: 33-43.

11. Barrier JH, Séréni D, Piette JC, Lévesque H, Ziza JM, et al. (2007) Continuing medical education and assessment of professional practice of general internist: Stake at issue and debate. Rev Med Interne 28: 813-817.

12. Dory V, Charlin B, Vanpee D, Gagnon R (2014) Multifaceted assessment in a family medicine clerkship: A pilot study. Fam Med 46: 755-760.

13. Johnson GA, Pipas L, Newman-Palmer NB, Brown LH (2002) The emergency medicine rotation: A unique experience for medical students. J Emerg Med. 22: 307-311.

14. Baranger L, Baron C (2011) État des lieux des apprentissages des pratiques gynécologiques des internes de médecine générale en stage ambulatoire. Exercer 97: 90-91.

15. Bigot P, Roupret M, Orsat M (2008) Évaluation des compétences pratiques en fin de deuxième cycle des études médicales : Exemple du drainage du bas appareil urinaire. Prog Urol 18: 125-131.

16. Lacasse M., Ratnapalan S (2009) Teaching-skills training programs for family medicine residents systematic review of formats, content, and effects of existing programs. Can Fam Physician 55: 902-903.

17. Malinovsky JM, Gardenal O, Barrier JH (2004) Assessment of teaching methods of anaesthesiology and intensive care medicine in France: Opinions of teacher and residents. Ann Fr Anesth Reanim 23: 124-131.

18. Yates JE (2013) Intern evaluation strategies in familymedicine residency education: What is-and is not-being done. Fam Med 45: 387-391.

19. Zaher E, Ratnapalan S (2012) Practice-based small group learning programs: Systematic review. Can Fam Physician 58: 637-642.

20. Oristrella J, Olivab JC, Casanovasa A, Cometa R, Jordanaa R, et al. (2014) The computer book of the internal medicine resident: Competence acquisition and achievement of learning objectives. Rev Clin Esp 214: 8-16. 